\title{
Examining Switching Intentions, Partial and Total Switching among Mobile Subscribers in Ghana
}

\author{
Simon Gyasi Nimako ${ }^{1}$, Joseph Mbawuni ${ }^{2}$ \\ ${ }^{1}$ Department of Management Studies, University of Education, Winneba, Ghana \\ ${ }^{2}$ Department of Accounting Studies, University of Education, Winneba, Ghana \\ Correspondence: Simon Gyasi Nimako, Department of Management Studies Education, University of Education, \\ Winneba, Ghana. E-mail: sim.ekomerce@gmail.com
}

\author{
Received: April 22, 2015 \\ Accepted: May 12, $2015 \quad$ Online Published: March 16, 2016 \\ doi:10.5539/ibr.v9n5p36 \\ URL: http://dx.doi.org/10.5539/ibr.v9n5p36
}

\begin{abstract}
This paper empirically explores consumer switching intentions, partial and total switching situations in the Ghana mobile telecom industry. Using data from a cross-sectional survey of 736 mobile subscribers from six global telecom networks in Ghana's mobile telecommunication industry, the results indicate switching intentions are significantly different among customers of various mobile telecom service providers. Customers of MTN and Tigo mobile operators have stronger intentions to switch than those from the other firms. It also found that more non-porters defect and switch to other mobile networks than porters do. Consistent with the hypothesis, defectors (partial switching) are strongly associated with total switching behaviour than non-defectors. Also, in order to reduce subscriber defect or churn rate, mobile telecom operators should direct more effort and resource to promoting and educating their customers on the benefits of porting their mobile numbers to other networks. Theoretical and managerial implications are discussed. The paper contributes to the body of knowledge in the area of consumer switching behaviour in mobile telecom industry in emerging countries.
\end{abstract}

Keywords: total switching, partial switching, mobile telecom networks, demography, binary logistics regression, chi-square

\section{Introduction}

The literature on consumer switching behaviour (CSB) has grown considerably within the last two decades since consumer switching continues to affect firm's survival, profitability and growth (Keaveney, 1995). Over the last decade much empirical research has be published on the subject of CSB in both competitive and non-competitive industries (Roos, Edvardsson \& Gustafsson, 2004), and across different service contexts (Bell, Auh \& Smalley, 2005; Chiu, Hsieh, Li, \& Lee, 2005; Balabnis, Reynolds \& Simintiras, 2006;Bansal, Taylor \& St. James, 2005;Bansal, Irving \& Taylor,2004;Morgan and Dev, 1994; Bansal \& Taylor, 1999b). Nimako (2012a) presented a comprehensive conceptualisation of the switching behaviour definition and typologies for the purpose of generating for further theoretical discourse and avenues for future research. Notably, the author pointed out that switching intentions may be different from actual switching behaviour (Roos, Edvardsson \& Gustafsson, 2004), although intentions might lead to actual behaviour (Ajzen, 1991; Ajzen \& Driver, 1992). Nimako (2012a) also pointed out that a complete or total switching process occurs where a customer breaks relationship with a current service provider (known as partial switching or defect) and moves on to develop a new relationship with another service provider. Partial and total switching incidences have important implications for marketing scholars and managers alike, especially in the mobile telecommunication industry context. Yet very little research work has been done to explore these interesting phenomena.

The telecom industry is an environment that provides evidence of different consumer switching behaviours in the wake of Mobile Number Portability (MNP), multiple phones use, multiple SIM use, and competition in the industry. Competition has been increasingly fierce in many mobile industries globally, and in African in particular. In Ghana mobile telecom industry (GMTI), the situation is not different as the six global mobile network service providers are competing strongly for market and customer share. According to available statistics by the industry regulator, National Communication Authority (NCA) (National Communication Authority, 2014), among the six mobile telecom operators in Ghana, in terms of Mobile Voice statistics, MTN Ghana maintained its position as the dominant mobile operator with its subscriber base increasing from $12,968,610$ to $12,986,832$ as at the end of February, 2014. This was followed by 
Vodafone Ghana with an increase in sub-scriber base from 6,244,855 ending January to 6,413,376 in February 2014, representing $22.41 \%$ of the total market share. This is followed by Tigo with sub-scriber base shooting up to 4,086,615 representing $14.28 \%$ of the market share at the end of the review month. Next in market share is Airtel Ghana with an increased subscriber base from 3,508,411 to 3,537,316 subscribers at the end of February, 2014, which represents $12.36 \%$ of the total market share. Glo Ghana's market share from January ending reduced from $5.17 \%$ to $5.02 \%$ as at the end of February 2014, with a sub-scriber base of 1,437,580. Finally, Expresso ended the month of February, 2014 with a market share of $0.54 \%$, as a result of a decrease in their subscriber base from 168,998 in January to 153,727 . Moreover, on July 7, 2011, the MNP policy was introduced in GMTI by the National Communication Authority (NCA) with the collaboration of the six mobile telecom operators. This has undoubtedly increase competition in the industry than ever before. The introduction of MNP, the use of multiple phones, and multiple network services by customers has, to a large extent, contributed to the intense competition as mobile subscriber churn rate tend to rise in GMTI for some firms more than others (National Communication Authority, 2014).

The problem of this study hinges on two important areas. First, in the wake of intense competition in the mobile telecom industry in many developing countries like Ghana, there is the need for empirical evidence on switching intentions and behaviour among consumers of competing mobile telecom networks in Ghana as a means of providing feedback for management strategy for each firm. This study hopes to fill this gap in advancing marketing practice.

Second, previous research has established that customers may exhibit different switching behaviours (Roos, Edvardsson \& Gustafsson, 2004; Bell, Auh \& Smalley, 2005; Chiu, Hsieh, Li, \& Lee, 2005; Balabnis, Reynolds \& Simintiras, 2006; Bansal, Taylor \& St. James, 2005; Bansal, Irving \&Taylor, 2004; Morgan \& Dev, 1994; Bansal \& Taylor, 1999b). However, investigations into partial and total switching incidences have received relatively very little research attention in the CSB literature as pointed out by Nimako (2012a). In mobile telecom industry, the mobile number portability platform allows consumers to switch while retaining their original mobile numbers (Buehler \& Haucap, 2004; Nimako, Ntim \& Mensah, 2014; Odunaike, 2010; Shin \& Kim, 2007). This implies that porting allows consumers to partially switch. This could in turn influence a consumer's decision to either defect a relationship with a current provider or completely switch to a new competitor. Investigating these switching behaviours could have useful implications for marketing theory and practice. Yet there is little empirical work in this direction. Based on the above discussion, the main purpose of this study is to explore the switching intentions, partial and total switching behaviour of consumers in Ghana mobile telecommunication industry. Specifically, the study sought:

1. To measure the switching intentions among consumers of six mobile telecom operators in Ghana.

2. To assess whether switching behaviour of customers are associated with mobile telecom brands (Expresso, Tigo, Airtel, Vodafone, Glo and MTN).

3. To assess the influence of porting behaviour on switching behaviour of consumers.

The rest of the paper is organized as follows. Relevant literature is reviewed and conceptual framework and hypotheses are proposed. It is followed by methodology, data analysis, and discussion of results and implications of findings. Then, limitations and directions for future research are discussed. It ends with a conclusion.

\section{Theoretical Framework and Hypothesis}

\subsection{Concept of Consumer Switching Behaviour}

Nimako (2012a) defined consumer switching behaviour as "the process by which a consumer abandons his/her relationship with a current service/product provider and replaces it with a competitor partially or entirely for a given time period." (p. 68). The author provided several conceptual dimensions and typologies of the CSB phenomenon in his switching typology tree (Fig. 1). Notably, he pointed out that switching is a process involving both a switched-from and a switched-to concepts that make a complete or full or total switch (Nimako, 2012a). In situation where a consumer defects or switch from one provider but does not proceed to switch to a new service provider, it is termed a partial switching behaviour. In many research contexts, the idea of switching represents a complete or total switch involving a consumer switching from one service provider to another (Nimako, 2012a). While negative factors existing at a current service provider, push factors, may cause consumers to defect (switch from), positive factors existing at a competitor service provider, pull factors, may attract consumers to switch to the competitor (Bansal, Taylor\& St. James, 2005).

Depending on the switching decision process, switching behaviour may be categorized further into several segments. These switching behaviour segments include those customers who actually switch, called Switchers (Njite, Kim \& Kim, 2008), those who may be considering a switch or have an intention to switch in the near future, termed considerers (Ofcom 2010), those who do not wish to switch at all in the near future even though they have some reasons to do so, termed non-switchers or stayers (Roos, Edvardsson \& Gustafsson, 2004], those switchers who return back to the former service provider, referred to as return switchers or return migrants (Bansal, Taylor \& St. James, 2005), and those 
switchers who keep on switching from many different service providers (habitual switchers) or polygamous buyers (Bansal, Taylor \& St. James, 2005).

It becomes critically important for management of firms to understand these consumer segment based on their switching behaviour for the purposes of managerial strategy. There is very little empirical studies that explore these segments of switching behaviour in specific industry contexts, and the theoretical relationship between partial and total switching behaviour in general and in a developing country mobile telecommunication industry in particular. This study area is crucial to consumer behaviour literature in that it will enhance further theoretical discourse into the critical factors that mediate the relationship between partial and total switching behaviour.

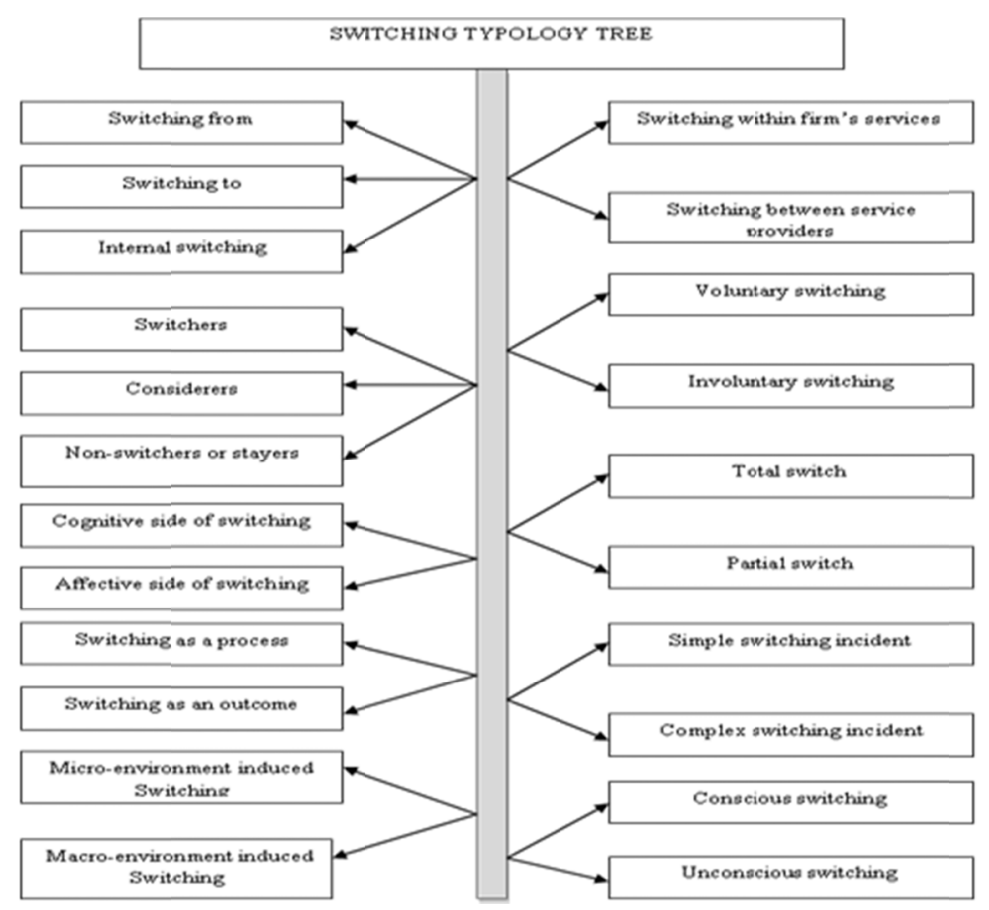

Figure 1. Switching typology tree. It depicts ten key typological dimensions of consumer switching phenomenon explained in the present paper. Source: adapted with permission from Nimako (2012a).

\subsection{Switching in Telecom Industry: Conceptual Framework and Hypothesis}

The conceptual framework (Figure 2) depicts that consumer switching in the telecom industry can occur in two principal ways, one is by defecting and the other is by porting their mobile numbers through the MNP platform.

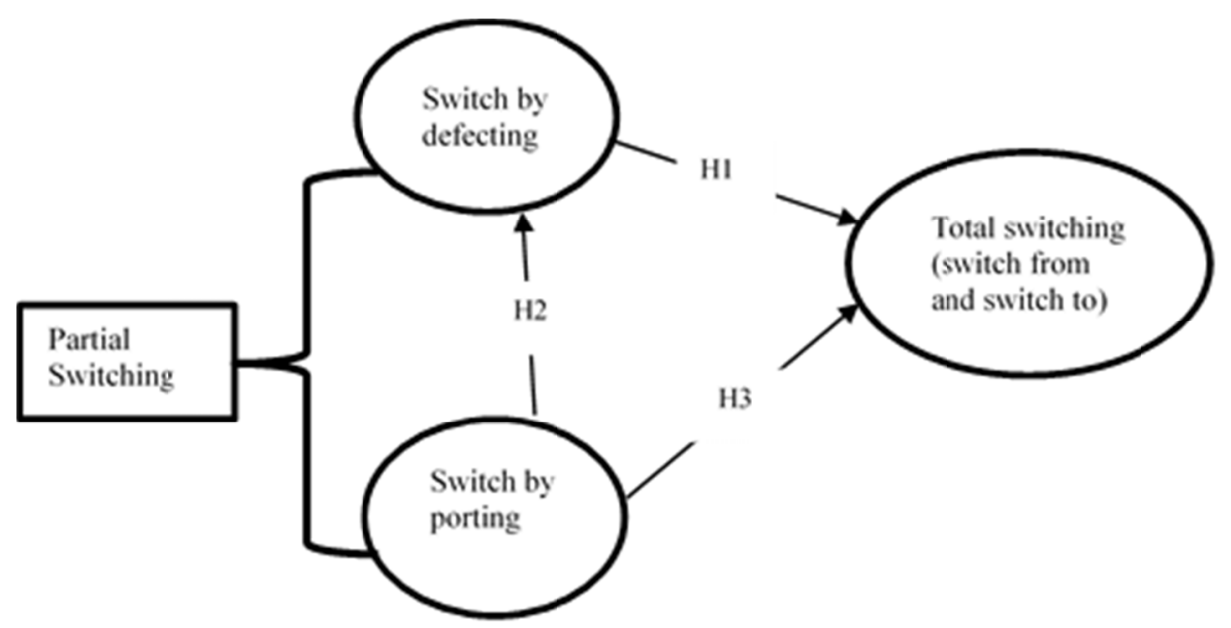

Figure 2. Conceptual framework and hypotheses

\subsubsection{Switching by Defecting}

Customers defect when they stop using the services of a service provider or they abandon their relationship with a 
service provider for any reason. In this situation, the service provider will record loss of customer base and therefore loss of market share in an industry. When customers defect it actually means they have broken relationship with a service provider, representing a switched-from phenomenon, which is only one side of the switching phenomenon. A complete or total or full switching process takes place when there is a switch from one service provider and a switch to another (competitor) (Nimako, 2012a). When a customer only switches from a service provider, that is defects, without switching to another, it constitutes a partial switching phenomenon. Partial switchers (defectors) are more likely to find new service providers, thus complete the total switching process. There is evidence in the marketing literature that show that defected customers search for new service providers (Keaveney, 1995). According to Keaveney (1995), 85\% of customer who defected also found new service providers through active search, while other found new providers through marketing communication such as direct marketing, sales promotion and advertising media. This happens when the customer realises that the same needs and wants for which he/she switched from a previous service provider could also be provided for by available competitors. In the competitive mobile network industries, like GMTI, where there are other strong competing firms, when a customer defects he/she is likely to search for and switch to new service provider, and thus, complete the switching process.

Therefore, it is expected that intentions to switch to a better service providers will be strongly associated with customers who switch from a former service provider (defectors) than those who do not switch. Thus, defectors are more likely to totally switch than non-defectors. This leads to the hypothesis that:

H1: Partial switching behaviour among defectors will be significantly associated with total switching behaviour among total switchers than among non-defectors. Specifically, defectors are more likely to totally switch than non-defectors.

\subsubsection{Switching through MNP Platform}

In the mobile telecom industry, especially in many emerging economies where the MNP has been introduced, consumers are also able to switch through the MNP platform by porting their mobile numbers to another mobile telecom network. This allows them to retain their mobile number and still be able to switch to use other telecom services. When customers port their mobile numbers, it signifies their desire and intention to switch to use the services of other networks while still retaining the mobile number of an existing service provider. Thus, the use MNP platform itself constitutes a partial switching phenomenon (Nimako, 2012a). In this situation, mobile subscribers are able to enjoy some services of other mobile telecom service providers which can influence them to either defect a current service provider and/or switch to a new one. Thus, switching through the platform of the MNP can cause customer to defect (partially switch) or switch to a new service provider (totally switch), especially when there is strong attraction from competitors (pull factors) or strong distractions from a current service provider (push factors). There is evidence in the marketing literature that when the attraction and opportunity to switch is strong, customers are more likely to switch than when the attraction is weak (Chiu, Hsieh, Li, \& Lee, 2005; Bansal, Taylor \& St. James, 2005; Zhang, Cheung \& Lee, 2012).

The above discussion suggests that porting behaviour is likely to influence switching behaviour in two ways. First consumers who port their mobile numbers (porters) are more likely to defect than those who do not port (non-porters). This is because as porters are exposed to use of other service providers' services they may perceive them to be better than their current providers' offerings, and therefore defect with a current service provider. Second, porters are more likely to make a decision to switch when they perceive themselves to be better off with a new service provider than their current service provider. Therefore, the following hypotheses are postulated:

H2: Porters are more likely to defect than non-porters. Specifically, more porters are likely to be defectors than non-porters.

H3: Porters are more likely to totally switch than non-porters. Specifically, more porters will be associated with a decision to switch to a new service provider (switchers) than non-porters.

\section{Methodology}

\subsection{Population and Sampling}

The population consisted of 26,591,124 individual subscribers as of April, 2013 (NCA, 2013) from all the six mobile telecommunication operators in Ghana, operating under these brand names: MTN Ghana Vodafone Ghana, Airtel Ghana, Tigo, Expresso and Glo Ghana. The appropriate sample size was estimated using sample size determination formula by Yamane (1967) that yielded an estimated sample size of 400. In order to collect data of high quality that reflect customers' opinion and have quality ofgood representativeness, a survey was conducted from a cross-section of subscribers of mobile telecom service providers across the country in July 2013. The survey yielded a usable 736 questionnaires returned representing $73.6 \%$ response rate for analysis. 


\subsection{Research Instrument}

Since this paper is based on a larger study in CSB in Ghana mobile telecom industry, the measurement items were part of the self-administered, structured questionnaire that was developed and pre-tested to a sample of twenty (20) customers. After adjustments were made based on the pre-test to get a more effective instrument, the questionnaire was finally administered to mobile subscribers through personal contact by researchers for nearly three weeks. For the purpose of this paper, the key variables are switching intentions, total switching behaviour, partial switching by adopters of MNP, partial switching by defecting, consumer background demograph and religiosity. Switching intentions were measured using three items on a five-point Likert scale was used, as recommended in previous work (Danaher \& Haddrell, 1996). Switching intention items were derived from previous study (Bansal, Taylor \& St. James, 2005). Total switching behaviour was measured by asking respondent whether they had switched or changed their mobile telecom network provider to new one within the past two years or not (yes/no response) Partial switching by defectingwas measured by asking respondents whether they had stopped being customers of any of the mobile network or not (yes/no response). Partial switching through MNP was measured by asking respondents to indicate whether they have ported their mobile numbers to anther network or not (yes/no response). The questionnaire also contained respondents' demographic data: gender, age, education, income, marital status, whether customer has ported their mobile number or not, and religiosity - the extent to which religious beliefs affect many important aspects of their life based on (Choi, 2010; Choi, Paulraj \& Shin, 2013).

\section{Data Analysis}

\subsection{Data Analysis Methods}

Apart from the use of simple descriptive statistics to describe categories of switching intentions and behaviour, a Chi-square test was also conducted to test the association proposed between porters, defectors, partial and total switching behaviour. Moreover, differences in switching intentions among customers of the six mobile telecom networks were analysed using a non-parametric ANOVA (Kruskal-Wallis ANOA) due to categorical sub-groups involved. Furthermore, the influence of background data onswitching behaviour was assessed using Binary logistics regression analysis since the variables involved acategorical dependent variable, switching behaviour, categorised as switchers (for yes response)and non-switchers (for no response). The logistics regression was chosen because of its soft non-parametric distributional assumptions (Hair, Black, Babin \& Anderson, 2010). All tests were conducted using asignificance value of 0.05 .

\subsection{Respondents' Characteristics}

For the characteristics of the respondents, in terms of gender, $67.7 \%$ of the respondents were males and $32.3 \%$ were females. $20.7 \%$ of the respondents were below 25 years, $67.3 \%$ of them were within the 7 ages of $25-36$ years, $11.4 \%$ were between 37 and 50 years, and .6\% were 51 years and above. This implies that majority of them were in the economically active population. All respondents were educated with about $58.7 \%$ of them having tertiary level of education, while about 5\% and 33\% had Senior High School (SHS) and post-SHS education respectively. About 3\% had other forms of education.

In terms of income, $33.5 \%$ of respondents earned monthly income up to US\$250, while $43.9 \%$ earnedbetween US\$250 and US $\$ 500$, about $6.5 \%$ earned monthly income above US\$ 500 . This indicates that most of them earned considerably low incomes. In terms of marital status, $61.7 \%$ of the respondents were married, about $36 \%$ were single (not married) and about $2 \%$ of them were in other marital category.

In terms of length of experience in using mobile network services, $9 \%$ of them had less than five years of experience, $56.1 \%$ of them had between 5 and 9 years of experience, $26 \%$ of them had between 15 and 19 years of experience and about $8 \%$ of them had over 20 years of mobile network service use. Generally, this indicates that most of respondents have had a considerable experience in the use of mobile network services.

About $16 \%$ of the respondents have ported their mobile phone numbers to another mobile telecom network (porters) while about $84 \%$ of them have not yet ported their mobile phone numbers to another network (non-porters). Based on their respective service provider's network, $5.4 \%$ of the respondents were customers of Expresso $(n=40), 7.5 \%$ of them were customers of Glo $(\mathrm{n}=55), 13.9 \%$ of them were customers of Airtel $(\mathrm{n}=102), 8.3 \%$ were customers of Tigo $(\mathrm{n}=$ $61), 24 \%$ of them were of Vodafone $(n=177)$ and $40.9 \%$ of them were from MTN $(n=301)$ respectively.

\section{Results}

The results are presented according to the research objectives addressed in this study.

\subsection{Differences in Switching Intentions of Customers}

Based on switching intentions, the results for different customer segments are presented in Table 1. From Table 1, the 
total of the three question items that were used to measure switching intentions indicate that, generally, $39 \%$ of the respondents were considering a switch (considerers), $24 \%$ are undecided and about $37 \%$ of the respondents are not considering a switching (non-considerers).

Table 1. Considerers, Undecided and Non-considerers of switching

\begin{tabular}{llllll}
\hline Segments of consumer switching behaviour & \multicolumn{2}{l}{$\begin{array}{l}\text { Considerers } \\
\mathbf{( 3 9 . 3 \% )}\end{array}$} & $\begin{array}{l}\text { Undecided } \\
\mathbf{( 2 4 \% )}\end{array}$ & $\begin{array}{l}\text { Non-considerers } \\
\mathbf{( 3 6 . 7 \% )}\end{array}$ \\
\cline { 2 - 7 } Switching intentions question Items/Scale & $\mathbf{1}$ & $\mathbf{2}$ & $\mathbf{3}$ & $\mathbf{4}$ & $\mathbf{5}$ \\
\hline $\begin{array}{l}\text { Do you have the intention of switching to use a better mobile } \\
\text { network services in the next year? }\end{array}$ & 125 & 179 & 173 & 128 & 131 \\
$\begin{array}{l}\text { How likely are you to switch from XYZ network to a different } \\
\text { network in the next two years? }\end{array}$ & 131 & 161 & 180 & 174 & 90 \\
$\begin{array}{l}\text { Are you considering changing from XYZ to a better mobile } \\
\text { telecom network soon? }\end{array}$ & 117 & 154 & 177 & 133 & 155 \\
\hline Total (\%) & $\begin{array}{l}\mathbf{3 7 3} \\
\mathbf{( 1 6 . 9 )}\end{array}$ & $\begin{array}{l}\mathbf{4 9 4} \\
\mathbf{( 2 2 . 4 )}\end{array}$ & $\begin{array}{l}\mathbf{5 3 0} \\
\mathbf{( 2 4 . 0 )}\end{array}$ & $\begin{array}{l}\mathbf{4 3 5} \\
\mathbf{( 1 9 . 7 )}\end{array}$ & $\begin{array}{l}\mathbf{3 7 6} \\
\mathbf{( 1 7 . 0 )}\end{array}$ \\
\hline
\end{tabular}

Note: Scale 1 - Definitely yes /Very likely, 2 - A bit yes/Likely, 3 - neutral, 4 A bit no/Unikely, 5 - Definitely no/Very unlikely

In terms of differences in switching intentions across mobile networks, a non-parametric One-Way Kruskal-Wallis ANOVA was chosen for the analysis since the strict assumptions parametric ANOVA were partially violated by the data gathered. The results of this tests are presented in Table 2 and Figure 3 for plot of mean ranks. Due to the rating scales used for the concept of switching intentions, the interpretation of the data should imply that low ratings represent high intentions to switch.

Table 2 indicates that consumer switching intentions differ significantly across mobiles networks for all the three measures of switching intentions, intending to switch: $\chi^{2}(5, \mathrm{n}=736)=118.531, \mathrm{p}=.000$, likelihood to switch: $\chi 2(5, \mathrm{n}$ $=736)=80.798, \mathrm{p}=.000$, and considering a switch: $\chi^{2}(5, \mathrm{n}=736)=124.637, \mathrm{p}=.000$. Specifically, MTN customers consistently appear to have the strongest intention to switch, followed by Tigo customers, while customers of Vodafone had lowest switching intentions, followed by Airtel and Expresso customers respectively.

Table 2. Differences in switching intentions among mobile networks

\begin{tabular}{|c|c|c|c|c|c|c|}
\hline \multicolumn{4}{|l|}{ Descriptive statistics } & \multicolumn{3}{|c|}{ Kruskal Wallis Tests } \\
\hline $\begin{array}{l}\text { Switching intentions question } \\
\text { items }\end{array}$ & Mobile network & $\mathbf{N}$ & Mean Rank & Chi-square & df & Asymp. Sig. \\
\hline \multirow{6}{*}{$\begin{array}{l}\text { Do you have the intention of } \\
\text { switching to use a better mobile } \\
\text { network services in the next year? }\end{array}$} & Expresso & 40 & 378.40 & 118.531 & 5 & 0.000 \\
\hline & Glo & 55 & 435.18 & & & \\
\hline & Airtel & 102 & 429.59 & & & \\
\hline & Tigo & 61 & 376.90 & & & \\
\hline & Vodafone & 177 & 468.84 & & & \\
\hline & MTN & 301 & 273.59 & & & \\
\hline \multirow{6}{*}{$\begin{array}{l}\text { How likely are you to switch } \\
\text { from AIRTEL network to a } \\
\text { different network in the next two } \\
\text { years? }\end{array}$} & Expresso & 40 & 401.40 & 80.798 & 5 & 0.000 \\
\hline & Glo & 55 & 429.03 & & & \\
\hline & Airtel & 102 & 421.27 & & & \\
\hline & Tigo & 61 & 369.08 & & & \\
\hline & Vodafone & 177 & 446.26 & & & \\
\hline & MTN & 301 & 289.34 & & & \\
\hline \multirow{6}{*}{$\begin{array}{l}\text { Are you considering changing } \\
\text { from AIRTEL to a better mobile } \\
\text { telecom network soon? }\end{array}$} & Expresso & 40 & 415.35 & 124.637 & 5 & 0.000 \\
\hline & Glo & 55 & 424.69 & & & \\
\hline & Airtel & 102 & 435.17 & & & \\
\hline & Tigo & 61 & 370.67 & & & \\
\hline & Vodafone & 177 & 468.50 & & & \\
\hline & MTN & 301 & 270.17 & & & \\
\hline
\end{tabular}

Note: Low ratings represent high switching intentions; $n=736$ respondents 


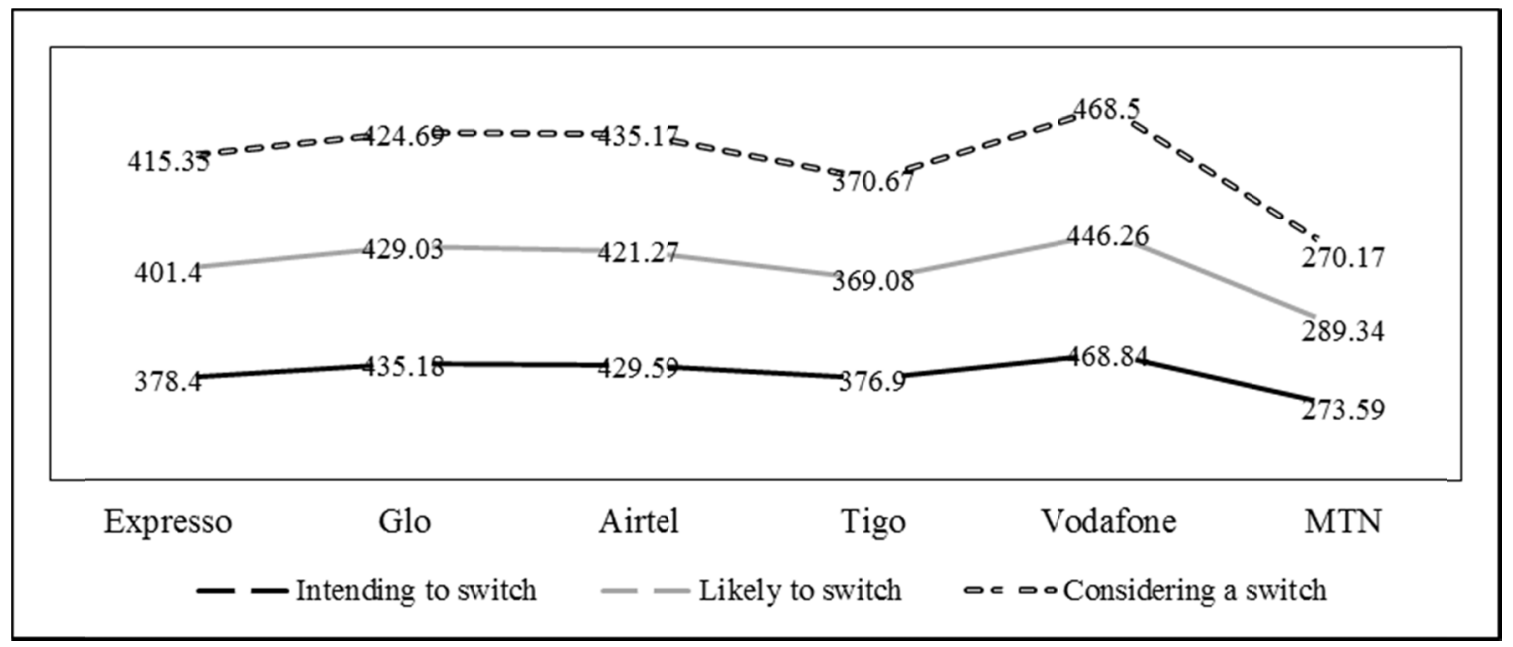

Figure 3. Switching intentions among mobile networks

Note: Low ratings represent high switching intentions; $\mathrm{n}=736$ respondents

\subsection{Differences in Subscriber Switching Behaviour among Networks}

A cross tabulation was conducted to find out about customer segments based on their switching behaviour and intentions. The results are presented in Table 3. From Table 3, subscribers or respondents who stopped using previous network (defected) and those who switched to other networks from a previous service provider (switchers) are presented. Generally, $55 \%$ of the respondents have fully switched and $37 \%$ have stopped defected or partially switched.

Across mobile networks, the greatest number of customers that have switched to other networks come from MTN (36.2\%), followed by Vodafone (24\%), Airtel (15\%), Glo (9\%), Tigo (5.2\%) and Expresso (6.8\%). In terms of customer defects, the greatest number of the defected customers are from MTN (33\%), followed Vodafone (24\%), Airtel (16.7\%), Glo (10.9\%), Tigo (8\%), and Expresso (7.30\%). From the analysis of chi-square tests (Table 3), switching behaviour in terms of both full switchers, $\chi^{2}(5, \mathrm{n}=736)=14.223, \mathrm{p}=.014$, $\mathrm{phi}=0.192$, and partial switchers, $\chi^{2}(5, \mathrm{n}=736)=$ $18.859, \mathrm{p}=.002, \mathrm{phi}=0.160$, were strongly associated with or dependent on mobile network group. The phi values of 0.192 and 0.160 respectively are considered small effect using Cohen's (1988) criteria of .10 for small effect, .30 for medium effect and .50 for large effect.

Table 3. Association between switching behaviour and type of mobile networks

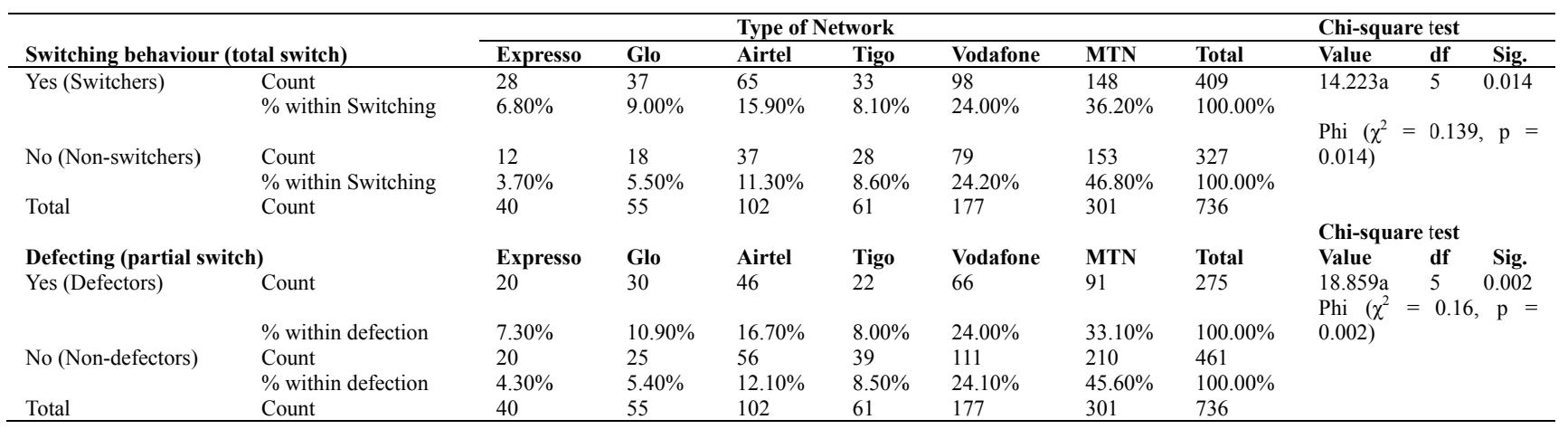

5.3 Influence of Porting Behaviour on Switching Behaviour

The results on the influence porting behaviour on switching behaviour are presented in Table 4 to assess hypotheses H1 to H3. From the Table 4, generally, $19.3 \%$ of the respondents who ported also ended up switching to other networks $(\mathrm{n}=79)$, while $80 \%$ of them did not end up switching to other service providers $(n=330)$. The Chi-square tests indicate that porting is not associated with total switching to another network. In other words, more non-porters switched to other networks than those who have ported their mobile, $\chi^{2}(1, \mathrm{n}=736)=6.116, \mathrm{p}=.013$. The phi of 0.192 indicates a small effect size using Cohen's (1988) criteria of .10 for small effect, .30 for medium effect and .50 for large effect. For porters, $21.8 \%$ of them also defected $(\mathrm{n}=60)$ and $78.2 \%$ of porters did not defect $(\mathrm{n}=215)$. The chi-square test confirms that defecting is more associated with non-porters than porters, $\chi 2(1, \mathrm{n}=736)=9.782, \mathrm{p}=.002)$. The phi of 0.115 indicates a small effect size using Cohen's $(1988)$ criteria of .10 for small effect, .30 for medium effect and .50 for large effect. In terms of defectors who finally switched to a new service provider $(n=236)$ they represent $85.8 \%$ while defectors who did not finally switch were 39 representing $14.2 \%$. 
Table 4. Association between porting behaviour and switching behavior

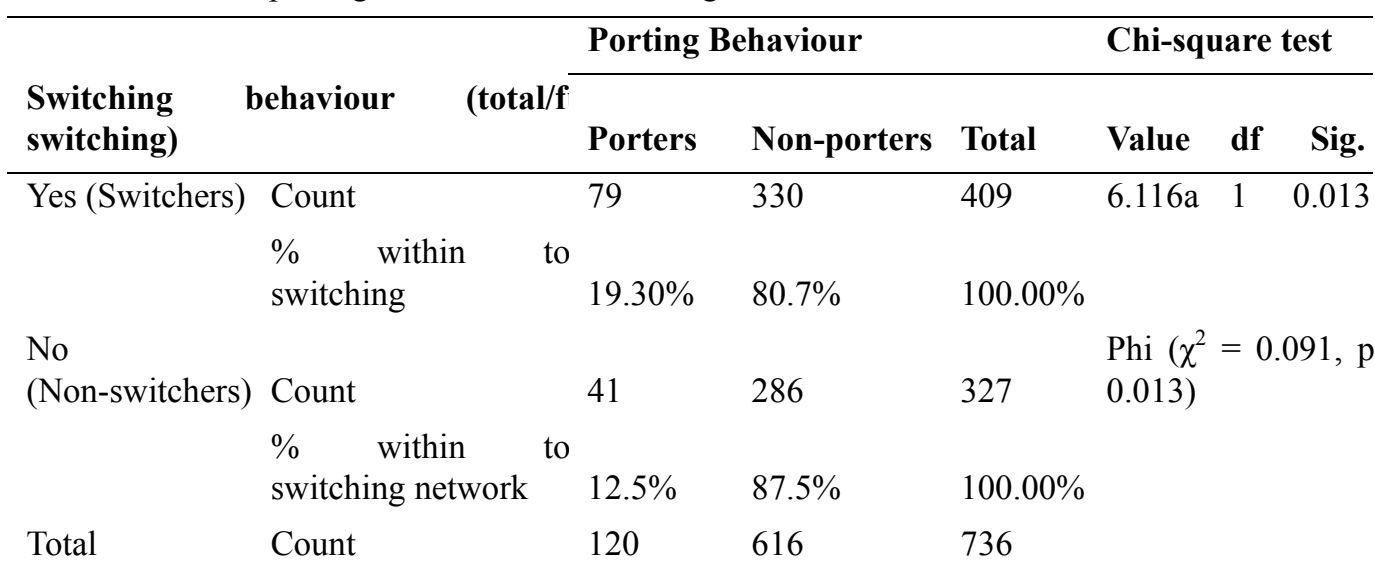

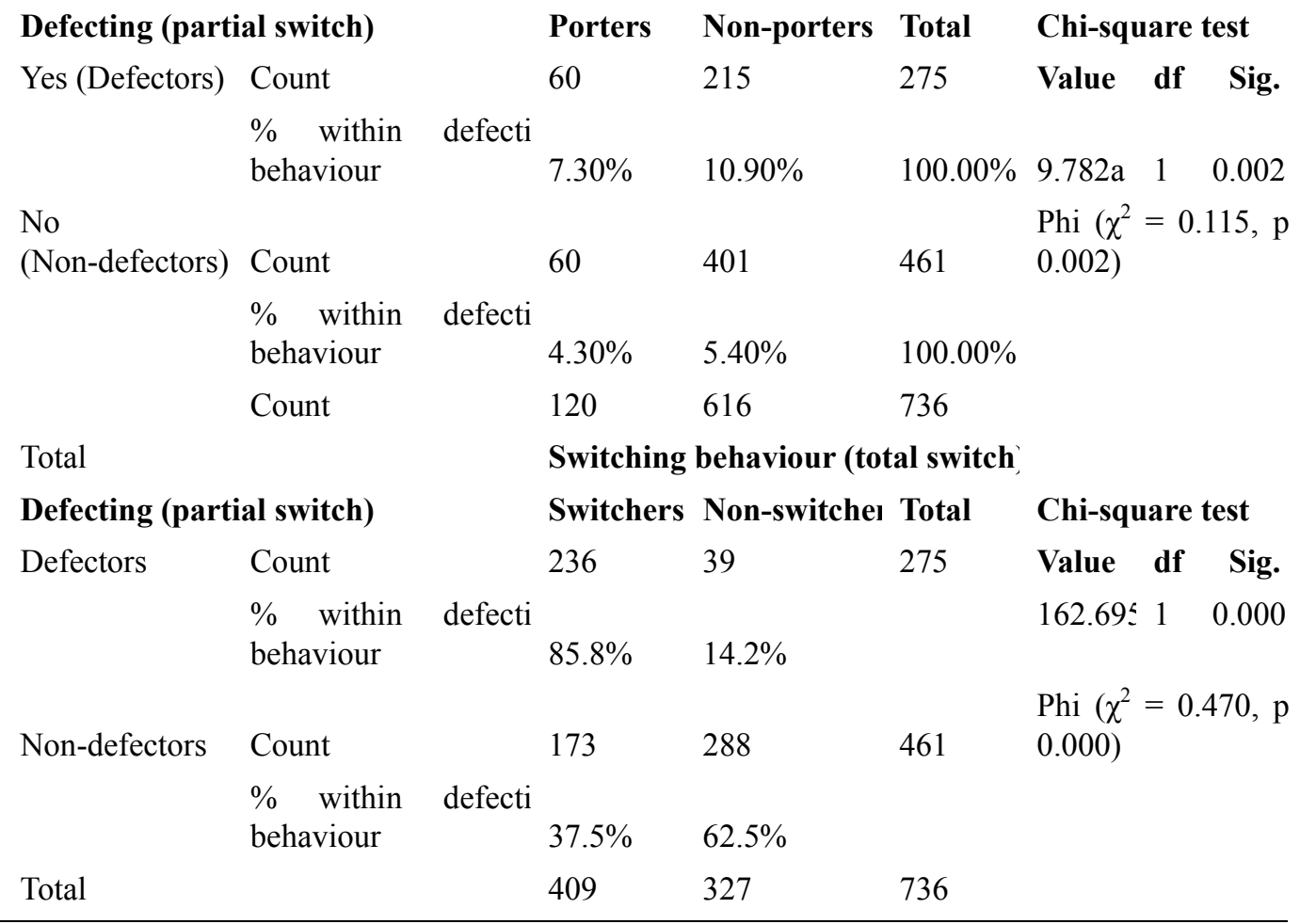

The chi-square test strongly suggests that more defectors significantly ended up switching to new service providers than non-defectors did, $\chi 2(1, \mathrm{n}=736)=162.695, \mathrm{p}=.002$. The phi of 0.470 indicates a medium effect size using Cohen's (1988) criteria of .10 for small effect, .30 for medium effect and .50 for large effect.

\subsection{Summary of Key Findings and Hypothesis Testing}

The key findings of the study and results of hypothesis testing are presented in Table 5. It indicates five key research findings, and shows that hypothesis H1 was supported by the data while hypotheses H2 and H3 were not supported. The implications of the key research findings and hypotheses are discussed in the next section. 
Table 5. Summary of Key Findings and hypotheses

\section{Key Results}

1. Switching intentions differ among customers of the six mobile telecom operators. Switching intentions were stronger among MTN customers than other networks.

2. Switching behaviour differ among mobile telecom operators. Most customers switch from MTN than from other networks

3. Porting behaviour differ among mobile telecom operators. Most customers switch from MTN than from other networks

4. Defectors are more associated with switching to new service providers than non-defectors.

5. Non-porters are more likely to switch to new service providers than porters do.

\section{Hypothesis}

H1: Defectors are more likely to totally switch than non-defectors.

$\mathrm{H} 2$ : Porters are more likely to defect than non-porters.

H3: Porters are more likely to totally switch than non-porters.

\section{Remarks}

Supported

Not supported

Not supported

\section{Reference}

Table 4

Table 4

Table 4

\section{Discussion and Implications}

For this study, the main purpose was to explore the switching intentions, partial and total switching behaviour of consumers in Ghana mobile telecommunication industry. The results and findings of the study provide empirical support for different consumer switching behaviour as conceptualized in previous studies (Roos, Edvardsson \& Gustafsson, 2004; Bansal, Taylor \& St. James, 2005; Nimako, 2012a; Njite, Kim \& Kim, 2008). The study also found some differences in switching intentions and behaviour among customers of the six mobile network operators in Ghana.

\subsection{Differences in Switching Intention and Behaviour among Mobile Network Operators}

First, the study found that consumers' switching intentions and behaviour significantly differ among the mobile networks. Specifically, customers of MTN brand have the strongest intentions to switch to other network operators than their counterparts from the other mobile telecom networks. Also, more switchers are also associated with MTN than the rest of the competitors in GMTI. Comparing this finding with what was found by previous researchers in 2009 (Nimako \& Azumah, 2009), there is strong evidence that MTN Ghana stand the risk of losing customers to other competitors in the next few years since consistently their customers expressed stronger intentions to switch. Generally, defectors and switchers are more associated with MTN than the other mobile networks as the results clearly point out.

The second company whose customers have significantly higher intentions is Tigo mobile telecom operator. This situation is different from what was found in 2009 where customers of Tigo had relatively lower intention to switching to other competitors (Nimako \& Azumah, 2009). This sharp contrast means that the company appears to be influencing their customers negatively. Thus, MTN and Tigo appear to be negatively influencing their customers and therefore causing them switch to competitors. This implies that there might be technical and functional quality issues of service delivery that these two companies missing out in meeting customers' desires and expectations (Nimako, 2012b; Nimako, 2012c). It might also be that other competitors in the industry are able to attract customers from MTN and Tigo. Such strong attractions are able to influence customers to develop strong intentions to switch (Bansal, Taylor \& St. James, 2005). It is important for the two firms to conduct further research into why their customers' have such stronger intentions to switch.

On the other hand, customers of Vodafone Ghana appear to have the lowest intention to switch; most of them are not considering a switch to other network, according to our finding. This finding suggests that the management of Vodafone has significantly improved upon its delivery of service quality and satisfaction of customers through effective service management strategies. Compared with their performance in 2009 when Vodafone went into management crisis that led to the switching of many of its customers to other firms in the Ghana's mobile telecom industry (Nimako \& Azumah, 2009), the new management appears to have been able to win back the confidence of existing customer and attracted new ones who have little intentions to switch.

Moreover, the findings indicate that customers of Glo, Expresso and Airtel also have relatively weak intentions to switch to networks. This implies that management of these companies should keep improving their service quality and value to customers in an attempt to influence customers' intentions to switch.

\subsection{Influence of Porting Behaviour on Switching Behaviour}

Two important findings of the present research are that, generally, porting behaviour is significantly associated with 
switching behaviour. Specifically, more non-porters defected and switched to other mobile networks than porters did, disproving hypotheses $\mathrm{H} 2$ and $\mathrm{H} 3$. One possible reason for this situation is that non-porters are likely to defect and switch completely when they have little or no knowledge about existing porting opportunities available to them through the adoption of MNP policy, which allows consumers to switch while still retaining their current mobile numbers (Buehler \& Haucap, 2004; Nimako, Ntim \& Mensah, 2014; Shin \& Kim, 2007).

Therefore, in order to reduce subscriber defect or churn rate, mobile telecom operators should direct more effort and resource to promoting and educating their customers on the benefits of porting their mobile numbers to other networks through the MNP platform. This can significantly influence the decision to defect among non-adopters of MNP since by adopting MNP they will be able to switch and still retain their existing mobile number. This will in turn benefit the existing service providers more than when their customers defect. Thus, one way to reduce customer churn rate is to encourage them to adopt MNP policy.

Second, it was found that defectors are more associated with total switching behaviour than non-defectors. Specifically, the results indicate that more customers who defected also switched to a new mobile network operator, providing support for hypothesis H3. One possible explanation for this finding is that, generally, when a mobile subscriber stops using the services of one network he/she is more likely to search for a new one for two reasons. One is the availability of strong competitors who can serve as comparable substitutes (Bansal, Taylor \& St. James, 2005). The other reason is that there might be strong perceived competitor attractiveness in terms of offerings and value for money (Bansal, Taylor \& St. James, 2005; Bansal, Irving \&Taylor, 2004; Morgan \& Dev, 1994; Bansal \& Taylor, 1999b). Where consumers perceive that they are likely to be better off with another service provider, they will be more likely to switch than to stay (Bansal, Taylor \& St. James, 2005; Bansal, Irving \&Taylor, 2004; Morgan \& Dev, 1994; Bansal \& Taylor, 1999b; Zhang, Cheung \& Lee, 2012; Gerrard \& Cunningham, 2004).

These findings imply that porting of mobile number may not necessarily be a significant factor that influence consumers' decision to completely switch to new service providers. This is because through the MNP platform consumers are able to enjoy other service providers' services while maintaining the current service provider. Therefore, they may not want to switch entirely in order to benefit from the current service providers. Another important implication of this findings is that industry regulators such as NCA would have to put in measure to increase competition among industry players in order to attract consumers to switching through MNP platform. MNP adoption as a platform to switch without financial cost might not be enough incentive to consumer to switching. Other factors such as high competition is important. Consumers might not switching unless they find it economically viable to switch to other competitors.

The results also show that non-porters, rather, are more likely to switch totally or completely to other competitors. Thus, MNP appears to be effective in inducing partial switching behaviour but not necessarily causing consumer complete or total switching behaviour, especially among consumer who have adopted MNP.

The findings also imply that defectors are also more likely to switch to new service providers in the mobile telecom industry than to return back to their former service providers. The implication for management is that mobile telecommunication managers could target defected customers of other competitor mobile networks and attract them through powerful and effective promotional strategies that promises them attractive offers and more customer value (Nimako, 2012b; Nimako, 2012c; Cronin, Brady \& Hult, 2000).

\section{Limitations and Future Research}

While the present study is particular useful to marketing theory and practice in the mobile telecommunication industry, it is limited in terms of the generalizability of the findings. This study is limited to only Ghana mobile telecom industry and thus, the findings are valid in the research context but may not be valid in other mobile telecom context in the Sub-Sahara Africa due to some significant differences that might be found in consumer culture and demography in various parts of the region. It is recommended that future research should examine cultural influence on switching behaviour, and other longitudinal studies should be conducted and the findings compared with some cross-section studies in CSB like that of the present study.

\section{Conclusion}

The main purpose of the present study was to explore consumer switching intentions, partial and total switching phenomenon in the Ghana mobile telecom industry. The study relied on cross-sectional survey to provide empirical evidence to address the research objectives. While there has been much interest in CSB in the last two decades, very little is empirically known regarding partial and total switching phenomenon which characterize CSB in mobile telecom markets, especially with the advent of MNP policy, multiple SIM and phone use and frequent switching incidences.

In the GMTI, the present study provides empirical evidence that switching intentions are significantly different among customers of various mobile telecom service providers. It found that, generally, defectors and switchers are more 
associated with MTN than the other mobile networks as the results clearly point out, and that switching intentions are strongest in MTN and Tigo customers.

It also found that more non-porters defect and switch to other mobile networks than porters do, and that such nonadopters of MNP are more likely to switch totally or completely to other competitors. Therefore, in order to reduce subscriber defect or churn rate, mobile telecom operators should direct more effort and resource to promoting and educating their customers on the benefits of porting their mobile numbers to other networks through the MNP platform. Thus, one way to reduce customer churn rate is to encourage them to adopt MNP policy.

It found that defectors are more associated with total switching behaviour than non-defectors. These findings imply that porting of mobile number may not necessarily be a significant factor that influence consumers' decision to completely switch to new service providers. The strongest influencer of switching behaviour is non-porting behaviour. Respondents who do not adopt MNP are more likely to switch to new service providers than those who adopt MNP. The study is limited in terms of industry context and future research has been proposed to extend the study to other research contexts regarding partial and total CSB.

\section{References}

Ajzen, I. (1991). The theory of planned behavior, Organizational Behavior and Human Decision Processes, 50, 179-211. http://dx.doi.org/10.1016/0749-5978(91)90020-T

Ajzen, I., \& Driver, B. L. (1992). Application of the theory of planned behavior to leisure choice. Journal of Leisure Research, 24, 207-224. http://dx.doi.org/10.1016/j.jbusres.2005.06.001

Balabnis, G., Reynolds, N., \& Simintiras, A. (2006). Bases of e-Store loyalty: Perceived switching barriers and satisfaction. Journal of Business Research, 59, 214-224.

Bansal, H. S., \& Taylor, S. F. (1999). The Service-Provider Switching Model (SPSM): A Model of Consumer Switching Behavior in the Services Industry. Journal of Service Research, 2, 200-218. http://dx.doi.org/10.1177/109467059922007

Bansal, H. S., Irving, P. G., \& Taylor, S. F. (2004). A three-component model of customer commitment to service provider. Journal of the Academy of Marketing Science, 32(3), 234-250. http://dx.doi.org/10.1177/0092070304263332

Bansal, H. S., Taylor, S. F., \& St. James, Y. (2005). Migrating to New Service Providers: Toward a Unifying Framework of Consumers' Switching Behavior. Journal of the Academy of Marketing Science, 33(1). 96-115. http://dx.doi.org/10.1177/0092070304267928.

Bell, S. J., Auh, S., \& Smalley, K. (2005). Customer relationship dynamics: Service quality and customer loyalty in the context of varying levels of customer expertise and switching costs. Journal of the Academy of Marketing Science, 33, 169-183. http://dx.doi.org/10.1177/0092070304269111

Buehler, S., \& Haucap, J. (2004). Mobile Numbering and Number Portability in Ireland. A report to the ODTR, Ovum, London. Journal of Industry, Competition and Trade, 4(3), 223-238. http://dx.doi.org/10.1023/B:JICT.0000047299.13443.5a

Chiu, H. C., Hsieh, Y. C., Li, Y. C., \& Lee, M. (2005). Relationship marketing and consumer switching behavior. Journal of Business Research, 58, 1681-1689. http://dx.doi.org/10.1016/j.jbusres.2004.11.005

Choi, Y. (2010). Religion, religiosity, and South Korean consumer switching behaviors. Journal of Consumer Behaviour, 9(3), 157-171. http://dx.doi.org/10.1002/cb.292

Choi, Y., Paulraj, A., \& Shin, J. (2013). Religion or Religiosity: Which Is the Culprit for Consumer Switching Behavior? Journal of International Consumer Marketing, 25(4), 262-280

Cronin, J. J., Brady, M. K., \& Hult, G. T. M. (2000). Assessing the effects of quality, value and customer satisfaction on consumer behavioral intentions in service environments. J. Retailing, 76, 193-218. http://dx.doi.org/10.1016/S0022-4359(00)00028-2

Danaher, P. J., \& Haddrell, V. (1996). A comparison of question scales used for measuring customer satisfaction. Int. J. Serv. Ind. Manag., 7(4), 4-26. http://dx.doi.org/10.1108/09564239610129922

Gerrard, P., \& Cunningham, J. B. (2004). Consumer switching behavior in the Asian banking market. Journal of Services Marketing, 18, 215-223. http://dx.doi.org/10.1108/08876040410536512

Hair, J. F., Black, W. C., Babin, B. J., \& Anderson, R. E., (2010). Multivariate Data Analysis, Englewood Cliffs, NJ: Prentice Hall. 
Keaveney, S. M. (1995). Customer switching behavior in service industries: An exploratory study. Journal of Marketing, 50(2), 71-82. http://dx.doi.org/10.2307/1252074

Morgan, M. S., \& Dev, C. S. (1994). An Empirical Study of Brand Switching for a Retail Service. Journal of Retailing, 70(3), 267-282. http://dx.doi.org/10.1016/0022-4359(94)90036-1

Moschis, G. P., \& Ong, F. S. (2011). Religiosity and consumer behavior of older adults: A study of subcultural influences in Malaysia. Journal of Consumer Behaviour, 10(1), 8-17. http://dx.doi.org/10.1002/cb.342

National Communication Authority (2014). Report on Mobile Voice Market Share. Retrieved on March 30, 2014 http://www.nca.org.gh/downloads/Telecom_Voice_Subscription_FEB_2014_1.pdf

Nimako, S. G. (2012a). Towards a Comprehensive Definition and Typology of Consumer Switching Behaviour: Unearthing research gaps. Research Journal of Social Science and Management, 2(3), 67-73.

Nimako, S. G. (2012b). Linking quality, satisfaction and behaviour intentions in Ghana's mobile telecommunication industry. Eur. J. Bus. Manag., 4(7), 1-17.

Nimako, S. G. (2012c). Prioritising Service Quality Dimensions in Ghana's Mobile Telecom Industry:Implications for Strategic Management and Policy. Asian Journal of Business Management, 4(3), 286-293.

Nimako, S. G., \& Azumah, F. K. (2009). An Assessment and Analysis of Customer Satisfaction with Service Delivery of Mobile Telecommunication Networks in Ghana. Master's thesis,LTU, Sweden.

Nimako, S. G., Ntim B. A., \& Mensah A. F. (2014). Effect of Mobile Number Portability Adoption on Consumer Switching Intention. International Journal of Marketing Studies, 6(2), 117-134. http://dx.doi.org/10.5539/ijms.v6n2p117

Njite, D., Kim, W. G., \& Kim, L. H. (2008). Theorizing Consumer Switching Behavior: A General Systems Theory Approach. Journal of Quality Assurance In Hospitality \& Tourism, 9(3). http://dx.doi.org/10.1080/15280080802412701

Odunaike, S. A. (2010). The Impact of Mobile Number Portability on TUT students On-line Connectivity. ISECON Proceedings, 27(1348).

Roos, I., Edvardsson, B., \& Gustafsson, A. (2004). Customer Switching Patterns in Competitive and Noncompetitive Service Industries. Journal of Service Research 6(256). http://dx.doi.org/10.1177/1094670503255850.

Shin, D. H., \& Kim, W. Y. (2007). Mobile number portability on customer switching behavior: in the case of the Korean mobile market. Info, 9(4), 38-54. http://dx.doi.org/10.1108/14636690710762129

Shin, D. H., \& Kim, W. Y. (2008). Forecasting customer switching intention in mobile service: An exploratory study of predictive factors in mobile number portability. Technological Forecasting and Social Change, 75(6), 854-874. http://dx.doi.org/10.1016/j.techfore.2007.05.001

Strategic review of consumer switching: A consultation on switching processes in the UK communications sector, p.31, 2010, Available: stakeholders.ofcom.org.uk/.../consumerswitching/.../switching.pdf

Yamane, T. (1967). Statistics: an introductory analysis. New York: Harper and Row.

Zhang, K. Z. K., Cheung, C. M. K., \& Lee, M. K. O. (2012). Online service switching behavior: The case of blog service providers. Journal of Electronic Commerce Research, 13(3), 184 -197.

\section{Copyrights}

Copyright for this article is retained by the author(s), with first publication rights granted to the journal.

This is an open-access article distributed under the terms and conditions of the Creative Commons Attribution license (http://creativecommons.org/licenses/by/3.0/). 